\author{
CONSUMER PRODUCT SAFETY \\ REGULATION IN THE UNITED \\ STATES AND THE UNITED \\ KINGDOM: THE CASE OF BICYCLES
}

Wesley A. Magat

Michael J. Moore

Working Paper No. 5157

\author{
NATIONAL BUREAU OF ECONOMIC RESEARCH \\ 1050 Massachusetts Avenue \\ Cambridge, MA 02138 \\ June 1995
}

This project has benefited greatly from the assistance of the U.S. Consumer Product Safety Commission, the Consumer Safety Unit of the British Department of Trade and Industry, and the U.S. National Science Foundation. Timothy Bresnahan, Philip Cook, Matthew Kahn, Howard Kunreuther, Robert Noland, Paul Portney, Gregory Rodgers, and an anonymous referee provided helpful comments. We are particularly indebted to Dr. Gordon Hayward of the Consumer Safety Unit for access to accident data and his help with understanding the British system of safety regulation and to the U.S. National Science Foundation for financial support. This paper is part of NBER's research programs in Health Care and Industrial Organization. Any opinions expressed are those of the authors and not those of the National Bureau of Economic Research.

(c) 1995 by Wesley A. Magat and Michael J. Moore. All rights reserved. Short sections of text, not to exceed two paragraphs, may be quoted without explicit permission provided that full credit, including $\mathbb{C}$ notice, is given to the source. 


\title{
CONSUMER PRODUCT SAFETY
}

REGULATION IN THE UNITED

STATES AND THE UNITED

KINGDOM: THE CASE OF BICYCLES

\begin{abstract}
We study the effects of bicycle safety regulations in both the United States and the United Kingdom on bicycle accident rates for various population age groups. We find small, statistically significant decreases in the accident rates as the stock of bicycles increases its compliance with the regulations. This result is independent of country, season, and trend effects and holds across a range of age groups. The results run counter to those in similar studies. This appears to reflect our focus on a specific standard, rather than on broad enabling legislation, and the longer time series available.
\end{abstract}

Wesley A. Magat

The Fuqua School of Business

Duke University

Durham, NC 27708
Michael J. Moore

The Fuqua School of Business

Duke University

Durham, NC 27708

and NBER 


\section{Introduction.}

In the United States, accidents inside the home, in the workplace, and outside of the home and work injure millions of citizens every year. In particular, accidents associated with consumer products injured about 30 million people in 1986 and resulted in 21,600 deaths. ${ }^{1}$ The consequences of these accidents impose a large and serious cost on the country, ${ }^{2}$ justifying extensive efforts to understand them. ${ }^{3}$

The traditional approach to attacking the consumer product safety problem has been the imposition of direct standards on product design. Paradoxically, the academic literature on the effectiveness of safety standards provides little evidence that design standards have any significant effects. Worse yet, this literature suggests that in some cases the standards can actually lead to increases in the frequency and severity of accidents.

In one of the best known studies, Peltzman (1975) found that automobile seat belt regulations were ineffective in reducing total fatalities from automobile accidents, with the results suggesting that drivers offset the risk reduction effects of wearing their seat belts by driving with less care. In another study, Peltzman (1987) finds little evidence that mandatory prescription legislation reduced the incidence of accidental poisonings and adverse reactions to drugs. Concerning the consumer product safety standards, Viscusi (1984a;1984b; 1985) found no significant evidence that the product specific standards set by the U.S. Consumer Product Safety Commission (CPSC) reduced consumer accident rates. For the specific regulation requiring child resistant packaging, Viscusi's results suggest that consumers may have been lulled into a false sense of 
security and lowered the levels of care they took in keeping medicines away from children.

From a policy perspective, these results are troubling to say the least, for they cast grave doubt on the efficacy of the primary mechanism used by most regulatory agencies to reduce safety risks, that of mandatory standards. Despite the findings that safety standards have not been effective in reducing risks and that alternative approaches such as information provision and taxes may be more effective (See Viscusi and Magat (1987), Magat and Viscusi (1992), and Moore and Viscusi (1989) ), interest in direct regulation of risky products persists for two reasons. First, information provision regulatory programs are difficult to design in ways that allow markets to function efficiently. Second, and most important for the purposes of this study, the principal findings in the direct regulation literature are subject to a number of limitations. Most of these unresolved issues revolve around the questions of data quality.

One troublesome aspect of available risk data is the lack of variation in the key risk measures, primarily due to small sample sizes. Linneman (1980) encountered data problems of this type in his analysis of the CPSC's 1973 mattress flammability standard using data from the National Institute of Burn Medicine. Point estimates indicate evidence of a large decrease in deaths during the period following the introduction of the standard. However, because the data include only thirteen annual observations, they do not appear to be rich enough to conclude that the decrease was statistically significant. Viscusi did use a long time series on aspirin and analgesic poisonings for his analysis of the child-resistant packaging regulations, but for the other CPSC regulations he was 
forced to either aggregate the accidents into broad categories such as poisonings, burns, and ingestion, or else study individual product regulations through an indirect injury rate forecasting approach that was necessary to deal with the small number of years of accident data available to him at the time of his study.

The lack of long time series on injuries subject to the specific standards issued by agencies regulating risk is another reason to be cautious in concluding that standards are not effective. An agency, such as the CPSC, is established by enabling legislation, but this legislation should not be expected to affect accident rates in and of itself, for it does not forbid any particular bebavior. The legislation is designed to reduce accidents by providing the agency with authority to issue standards for specific products and hazards. Thus, even with the strong evidence of little or no effects of the enabling law on aggregate accident rates, there may be sizable effects of specific regulations on particular products and hazards. In the product safety area, there have been few analyses of the standards regulating specific products.

We analyze one particularly important set of standards, those applying to bicycle safety, using monthly data on bicycle accident rates from both the United States and the United Kingdom. The purpose of our study is to definitively assess whether bicycle safety standards have resulted in fewer accidents in the United States and Great Britain. Section Two describes the structure of consumer product safety and bicycle regulation in the United States and the United Kingdom, including both the enabling statutes and the specific regulations affecting bicycle safety. Section Three reviews the sources and types of data we rely upon. Section Four presents our results on the effectiveness of the 
bicycle safety standards promulgated in the two countries, with the final section drawing conclusions about the implications of these results for regulatory policy.

\section{Consumer product safety regulation.}

\section{Enabling statutes}

In the United States the 1972 Consumer Product Safety Act established the Consumer Product Safety Commission, which began operation on May 14, 1973. The CPSC was charged with enforcement of several laws that had previously been distributed throughout several federal agencies, specifically, the Federal Hazardous Substances Act, the Poison Prevention Packaging Act, and the Refrigerator Safety Act. The CPSC has the authority to promulgate consumer product safety standards that protect consumers from "unreasonable risks" of injury from consumer products, to ban products that present "unreasonable risk of injury" and for which no feasible standard would protect the public adequately, and to recall and/or bring to the public's notice products which present an "imminent hazard."

Since its inception in 1973, the CPSC has issued 21 mandatory safety standards, 6 product bans, and 4 information and labeling requirements covered in 36 Part Numbers in the Code of Federal Regulations (See Code of Federal Regulations (1990)). Its initial attempts to reduce product-related accidents consisted largely of standards that sought to limit risk through technological means, either by eliminating the products altogether or by altering aspects of their design. The pace of regulatory activity at the CPSC slowed considerably in the early 1980 's. The 1981 amendments to the commission's enabling statute also pushed the agency towards heavier reliance upon 
voluntary standards prepared by industry groups, as well as public information campaigns. However, recently there has been somewhat of a resurgence of interest in design standards and product recalls, particularly with respect to risks to children. For example, the manufacture of lawn darts, which had been responsible for a small but increasing number of child fatalities in recent years, was ordered ceased in 1988.

The shifting emphasis of the CPSC reflects the underlying uncertainties about the appropriate form and extent of regulatory intervention. Many analysts and public officials call for continued reductions in CPSC activities, based in part upon the absence in research on the effects of existing standards of any discernible effect on risk levels. However, many others advocate continued direct interventions, such as the lawn dart ban, because the problems caused by unsafe consumer products simply refuse to disappear.

These problems reflect four basic facts. The most important of these remains the large number of accidents caused by consumer products. Second, the explosive growth of the product liability system continues to generate an increasing burden on the courts. Third, a number of analysts now feel that the product liability burden extends to firm decisions regarding new product development and innovation as well (See Viscusi and Moore (1993) ). Finally, some domestic firms now find themselves hard pressed to compete with foreign producers who may be insulated from the risks of product liability losses.

The system of regulating the safety of consumer products is similar in the United Kingdom. The Consumer Protection Act of 1961 and the Consumer Safety Act of 1978 
established and strengthened the authority of the Secretary of State to set product specific standards, as well as to ban and recall products. ${ }^{4}$ Twenty regulations were made under the 1961 Act, while 14 regulations and eight prohibition orders were issued under the 1978 Act.

In 1987 the Consumer Protection Act further strengthened the regulatory powers of the Secretary of State by establishing a "general safety requirement." This requirement created the obligation of consumer goods sold on British markets to be "reasonably safe having regard to all the circumstances," including the manner and purposes for which the goods are marketed, warning labels used, safety standards in existence, and other reasonable means for making the goods safer. The Act also maintained the Secretary of State's right to issue product-specific safety regulations, prohibited businesses from providing misleading information about prices, and imposed civil liability for damage caused by defective products at all points in the supply chain. Bicycle safety standards

During the period from the beginning of the U.S. data base (described below) in December, 1972, to October 1, 1978, when the sample was modified, the CPSC promulgated a set of performance requirements for all the major assemblies on bicycles. Several dates are potentially relevant to identification of possible effects of the regulation. On July 16, 1974, the "final" regulation was published, to be effective on January 1, 1975. However, on December 16, 1974, that standard was suspended for further amendment. On November 13,1975, the "revised final" standard was published covering areas such as braking, steering, wheels, sharp edges, protrusions, and 
reflectorization..$^{5}$ Most of the provisions of the standard became effective on May 11, 1976, with certain provisions for chain guards and footbrakes taking effect on November 13, 1976. In addition, CPSC implemented an extensive education and information program directed at 16,000 industry representatives.

As in the United States, the government of Great Britain passed a bicycle safety regulation; however, the British regulation's supply prohibition was not put into effect until August 1, 1984, almost ten years after the implementation date of the American regulation. The British regulation requires that all bicycles sold in the U.K. meet the 1981 and 1982 standards set by the quasi-governmental body, the British Standards Institute. British Standards are similar to voluntary standards in that they do not have the force of law, but many manufacturers comply with them and label their products to let consumers know that their products are in compliance.

\section{Data.}

\section{United States}

The primary data set on bicycle accidents in the United States for this study was constructed from the National Electronic Injury Surveillance System (NEISS) of the CPSC. NEISS collects detailed reports of accidents involving bicycles (and other products) from a probability sample of hospital emergency rooms throughout the country. For every injury treated, each participating hospital reports the date of treatment, up to three products involved, type and severity of injury, disposition of the patient, age and sex, where the accident occurred (e.g., in the home), whether it was work-related, and whether fire or a motor vehicle was involved. 
Starting in December of 1972, NEISS began collecting data from a sample of 119 hospitals. Weights were provided to make the sample representative of all hospitals with emergency rooms in the continental 48 states. In order to improve the initial data collection system, on October 1, 1978 a redesigned NEISS was implemented. This system collected data from 74 hospitals comprising a probability sample of hospitals with emergency rooms in all 50 states and the U.S. territories. As of 1984, the sample was changed to 64 hospitals that together treat about 200,000 consumer product-related injuries every year. ${ }^{6}$ Because the pre- and post-October 1,1978 samples are so different, we restrict our attention to the pre-1978 data.

Aggregate published NEISS data for the period subsequent to our sample show a levelling off of injury rates for the youngest age groups. Figure 1 depicts these trends. Among the 5-14 year old cohort, where injury rates are highest, injuries per 100,000 population equalled 868 in 1977, and 863 in 1988, the last year for which we have data. There is some evidence that injury rates rose from 1981-86 in the graph, and then began a steady decline, but the overall picture is one of a fairly constant injury rate. Similar patterns are observed for the other two series, which represent injuries for ages $0-4$ and 15-24. These relatively flat trends contrast with accident trends in general, which declined steadily over the same period (See, for example, Statistical Abstract of the United States, 1993, Table 126).

We aggregated NEISS data, which report individual accidents, by product code to produce the monthly bicycle accident series. ${ }^{7}$ In addition, we divided the bicycle accident series into several age categories to enable us to focus on the accident rates for the age 
categories of product users most affected by the regulations. We divided the accident counts by estimates of the number of bicycles in use to yield an estimate of accidents per million bicycles in use. ${ }^{8}$

Four injury rates were available to analyze the regulations. From the sample of hospitals reporting in NEISS, we calculated URATE, an unweighted measure of the accident rate in the NEISS sample denominated in units of reported accidents per million bicycles per month. NEISS provides sample weights with the data that can be used to estimate the number of injuries in the entire country. These weights were used to translate URATE into VRATE, the national estimate of the accident rate per million bicycles per month. NEISS also provides a measure of the severity of the injury coded on a scale from 2 to 8 , with 8 indicating death. We used these severity weights to calculate WRATE, a severity-weighted version of URATE, and XRATE, a severityweighted version of VRATE. We report only the VRATE results because our analysis led to no different conclusions based on the other three accident rate measures. In addition, the number of hospitals sampled changed slightly every year, making the URATE and WRATE figures unreliable for direct analysis.

The regulation variable used to evaluate the U.S. standard is constructed from information on bicycle sales, combined with assumptions about average product life. The variable \% Complying equals the proportion of post-regulation bicycles in use complying with the CPSC standard, based on estimates in Rodgers (1988). Two assumed product life assumptions were analyzed: seven and ten years. The November, 1975, date of publication of the "revised final" standard was used to construct the \% Complying 
variable, although the results are not sensitive to the use of other relevant starting dates around this same time.

The CPSC Annual Reports and the Code of Federal Regulations provided descriptions of the bicycle standards and their relevant dates such as those for proposal, promulgation, suspension, and court orders, as well as the dates the standards became effective.

\section{United Kingdom}

The Home Accident Surveillance System (HASS) managed by the Consumer Safety Unit of the British Department of Trade and Industry provides data quite similar to those in the NEISS data base. The HASS data cover the period from October, 1979, to October, 1990. Again, a representative sample of hospitals sends injury reports to HASS. The sample consisted of 20 hospitals until 1988, when it increased to 22 , and in 1990 it decreased to 18. All of these hospitals are in England and Wales.

Similar information is reported for each injury, that is, the date, type of injury, products involved, disposition of the patient, age, and sex. The main difference between the two data bases is that HASS only covers accidents in the home and yard, whereas NEISS includes all product-related accidents resulting in an emergency-room visit, and that HASS contains only non-fatal accidents. Home accidents are about $33 \%$ of all accidents treated in hospitals. ${ }^{9}$

We used the HASS data and estimates of the number of bicycles in use to calculate monthly injury rates associated with bicycles, with separate rates calculated for each age category. Sample weights provided by the Consumer Safety Unit were used to 
translate the accident rates for the hospital sample into an estimate of the national accident rate. Number of bicycles was estimated using data on miles per bike, miles ridden per person, and population. The injury rate variable used is injuries per million bicycles, as in the United States data. ${ }^{10}$

\section{Results.}

\section{United States results}

The bicycle regulations were designed to protect children as they are involved in the most accidents, but the regulations also applied to bicycles sold to adults. In order to capture this differential effect across ages, we examined the monthly accident rates separated into 5-year age groups. Table 1 shows that the base accident rates climb rapidly from the youngest age group ( $<5$ years old), with a mean $V R A T E$ value of 28.6 accidents per million bicycles per month, to a rate of 77.7 per million for age group 5-9 and a rate of 62.6 per million for ages 10-14. ${ }^{11}$ Although the 15-19 age group has a fairly high base accident rate averaging 14.2 per million bicycles, for riders older than teenagers the base accident rate declines rapidly with age. Thus, we would expect to find the largest effects of the bicycle standard on these younger age groups.

It is instructive to compare the data in Table 1 to the population injury rates in Table 2. The Figure 1 data indicate that, for example, the 5-14 year old population experiences about 1 accident per 100 population annually. If $75 \%$ of the members of the cohort use bicycles, the rate is 1.3 per 100 bicycles. The accident rate for that same cohort reported in Table 1 is about 850 per million bikes per year. If the same cohort uses $20 \%$ of the bicycles, this implies a true rate of 4200 per million bicycles, or .42 per 
100, which is about one-third the comparable Figure 1 estimate. This suggests a possible overstatement in the estimated number of bicycles, perhaps due to the product life assumption. Fortunately, if the overstatements are fairly constant over time, the regression estimates are not affected.

Table 2 provides some intuition about the impact of the bicycle standard on different age groups by comparing both average accident rates and average accident growth rates before and after the November, 1975, date of the standards. Comparison of the pre- and post-regulation means in columns 1 and 2 reveals that prior to the regulation the accident rate was higher for all age groups. Similarly, accident growth rates are higher before the regulation for the three youngest age categories, where the majority of accidents are concentrated.

Figure 2 provides some insight into the behavior of the injury processes. In Figure 2, separate graphs are presented for each season and for each of the four youngest age groups. The regulatory intervention appears as a vertical line at month 45 , which represents November, 1975. The median injury rates within each year are connected to illustrate the broad injury trend.

In the majority of cases illustrated, there is a downturn in the injury rate around the time of the intervention. This downturn appears at some times to be part of a general downward trend, but at other times does not. The overall picture is of a fairly consistent regulatory effect around the time of the regulation.

Table 3 presents estimates of the accident rate model using data for the 0-5 year age group under a range of specification assumptions. The dependent variable in the 
U.S. regressions is the natural log of accidents per million bicycles in use, where the number of bicycles in use is calculated as described above. ${ }^{12}$ Variations in the estimated models reflect the inclusion of a time trend variable and a correction for autocorrelation.

The basic model for age group $i$ is of the form

$$
\begin{aligned}
\text { Rate }_{\mathrm{it}}=\beta_{\mathrm{i} 0} & +\beta_{\mathrm{i} 1} \% \text { Complying }_{\mathrm{t}}+\beta_{\mathrm{i} 2} \text { SEASON DUMMIES }_{\mathrm{t}} \\
& +\beta_{\mathrm{i} 3} \text { TREND }_{\mathrm{t}}+\varepsilon_{\mathrm{i} t} .
\end{aligned}
$$

As Table 3 illustrates, the regulation significantly decreased reported injuries for the youngest age group. According to the estimates, a unit increase in \% Complying would decrease the log of the accident rate per million bicycles by $2.5-3.2$. At the mean value of the \% Complying variable of 0.15 , this yields an elasticity of $0.38-0.48 .^{13}$ Thus, extrapolating linearly, a further increase in the \% Complying variable to .25 would reduce the accident rate by $3.8-4.8 \%$. The remaining coefficients describe the general features of the injury series: most bicycle accidents occur in the summer months, followed by spring and fall, with the lowest accident rate in the winter. There is no evidence of a trend in the accident rate series for this age group.

Table 4 summarizes the key coefficient estimates for the remaining age groups of interest, using the most general model (with trend and $\mathrm{AR}(1)$ correction). The upper panel of Table 4 provides estimates under the seven-year product life assumption, while the lower panel assumes a ten-year product life. Consistent evidence of a regulatory effect is evident for the three youngest age groups (0-5, 6-10, and 11-15) under either product life assumption. For ages $\mathbf{2 1 - 2 5}$ (and beyond), there was little evidence of a change in the accident rate process as the stock of bicycles became newer. 
It is useful to interpret these results in light of overall trends in the bicycle industry over the sample period. Following a period of steady increase, there was a substantial jump in bicycle sales in the years 1972-74. Subsequent to 1975 , the number of bicycles sold fell by $40 \% .^{14}$ Since this decline corresponds to the period in which the regulation was introduced, we must consider whether the estimated effect of the change in the mix of new bicycles reflects the use of safer bicycles, or the effect of whatever market forces led to the decline in sales.

It seems plausible that the increase in sales in the early part of the 1970 s reflected the dramatic increase in gasoline prices. Suppose we accept the hypothesis that the increase in ridership in the $1972-74$ period contained a large proportion of "new" riders seeking alternatives to motor vehicles who were less experienced and, consequently, more likely to have an accident. Following a period of experimentation with bicycle transportation, some portion of these relatively unsafe riders might cease to use their bicycles, causing observed injury rates to fall due to a change in the mix of safe versus unsafe riders (rather than the richer mix of safe versus unsafe bicycles caused by the regulation).

The primary evidence that this rider mix effect is not a sufficient explanation for the observed effect of the \% Complying variable lies in the results for the youngest and older age groups. Everyone younger than five (and arguably up to ten) years old is a new rider, so that the differences in experience are implicitly controlled for in this age group. Consistently strong effects of the \% Complying variable are found for these age groups which the rider mix hypothesis cannot explain, thus ruling out this competing 
explanation for the decline in bicycle accident rates. Likewise, the rider mix effect should be operative among older age groups (e.g., 20-50), yet we found no evidence of a safety effect there.

The regulation was likely to have led to higher costs and thus higher prices, causing unit sales to decline. The regulation reduces bicycle accidents both by making bicycles safer to ride and by lowering the stock of bicycles in use. Of course, this latter effect could also lead to increased use of older, less safe bicycles which would have had the effect of increasing the accident rate. Our results indicate an improvement in safety despite this possibility.

The only published studies of the CPSC bicycle regulations that we are aware of are contained in Viscusi (1985), Petty (1987), and Rodgers (1988). Because he was forced to depend upon annual rather than monthly data and had relatively few observations after the regulation was published, Viscusi used a long time series (about 30 years) of data on an aggregate of all home accidents to predict the post-regulation bicycle accident rate, comparing the actual bicycle accident rate to the predicted rate. Since Viscusi found the actual rate to exceed the predicted rate, he concluded that if there had been any beneficial effect of the standard, it was obscured by factors that raised the injury rate, such as the increased intensity of bicycle use. Note also that the bicycle series shown in Figure 1 does not trend downward over a period in which the overall accident rate was declining. Our approach avoids the need to predict bicycle injury rates based on an analysis of accidents from the much wider class of all home accidents. ${ }^{15}$ We do, however, use a shorter time period. 
Petty extended Viscusi's analysis to 1985 using a different approach and the NEISS data, and confirmed Viscusi's results. However, he used simple correlation analysis of annual data with results highly sensitive to the change in accident rates due to redesign of the NEISS sample starting in November 1978, whereas we use data ending in October, 1978, thus avoiding this confounding factor.

Rodgers controlled for the NEISS sample change in November, 1978, and found a negative, but statistically insignificant, effect of the standard on bicycle accidents. Rodgers' results bear further discussion, as his design is similar to ours, while his results are less strong. Rodgers uses data before and after the NEISS design was changed, and controls for the change using a dummy variable, whereas we restrict our analysis to the pre-design change sample. He also includes variables for number of riders per bike and helmets per bike, using Petty's (1987) calculations. We do not report results using these variables. In two of Rodgers' specifications (injuries and head injuries), riders per bike has a significant positive effect, in one it is insignificant (lower trunk injuries), while in another (death), it is negative and significant. The helmet variable also increased less severe injuries. Furthermore, Petty's data indicate that helmet use began relatively late (1978) in our sample period, except for a minute fraction of riders. We assume that the effects of per bike ridership, which increases more or less monotonically over the sample period, are captured by the trend variable. The period of time covered by our sample largely precedes the widespread use of helmets, so we do not consider this effect either.

Other differences between our study and Rodgers are the use of monthly rather than annual series, and our disaggregation into age groups. Of these, it seems most 
likely that the disaggregation causes the difference. Our results appear only in the youngest age groups, while we find no effect among older riders.

\section{United Kingdom results}

Table 5 displays the pre- and post-regulation mean injury rates per million bicycles and their growth rates, based on weighted HASS data, for each age category of bicycle users in the United Kingdom, and Figure 3 plots the series by season and age group. To construct an injury measure similar to that used in the U.S. data, we combined an estimate of accidents per person, derived from the HASS data, with estimates of bicycle miles per person to estimate accidents per mile. We then multiplied this measure by an estimate of average miles travelled annually per bicycle to arrive at the estimate of accidents per bicycle in use. ${ }^{16}$ As Table 5 indicates, the accident series are broadly similar to their U.S. age-specific counterparts, with the exception of the youngest age group, where the U.K. accident rate is much higher. ${ }^{17}$ We used the U.S. product life model to construct a measure of the stock of bicycles and the mix of bicycles in compliance with the U.K. regulations. To control for broad trends and for seasonal effects, we again include a trend and seasonal dummy variables. The estimating equation for the U.K. data is thus identical to that for the U.S. data, with one exception: we are forced to drop observations corresponding to zero accident rates in the two older age groups. ${ }^{18}$ Again, the results are not sensitive to minor variations in the starting date of the regulation, in this case, August, 1984.

Table 6 presents estimates of the injury rate models corresponding to those in Table 3. There is weak evidence of a regulatory effect shown here. The regulation 
effect is negative and significant in two cases, but these cases correspond to the omission of the trend variable. Thus, we cannot conclude that the change in the accident rate reflects the effects of the regulation, rather than some underlying trend. Note that the trend effect is negative and statistically significant in both columns 2 and 4.

The results in Table 7 are more consistent with the results from the U.S. For the two age groups 5-9 and 15-19, the U.K. regulation caused a significant reduction in the accident rate, controlling for trend and seasonal effects, and for autocorrelation. As was the case in the U.S., no consistent effects are observed in older age groups. The U.K. results are also insensitive to the two specification assumptions, with the exception of the results shown in Table 6.

The estimated elasticities are smaller in magnitude than those in the U.S. In the 6-10 year old age group, a $10 \%$ increase in the percent of bikes complying, at the mean value of $\%$ Complying of $.18 \%$, would reduce the accident rate by $.7 \%$, or about oneseventh the estimate in the U.S. The percent reductions are similar for the remaining two cohorts.

\section{Conclusions.}

Earlier studies of the effectiveness of consumer product safety regulation in the United States tended to focus on aggregate accident statistics, and those that analyzed individual regulations were limited by a paucity of data. We are not aware of similar studies of consumer product safety regulation's effectiveness in other developed countries. In the intervening time, new data have become available on accidents associated with specific regulations in both the United States and the United Kingdom, 
allowing a reassessment of the conclusions of the earlier studies based on the new evidence. Since mandatory standards on the construction of bicycles were issued in both countries and this regulation was one of the most controversial ones issued by the CPSC, we chose to analyze closely the impacts of the bicycle safety regulations.

We find a significant effect of the safety standards in reducing bicycle accident rates both in the United States and in Great Britain. Our best estimates suggest that the standards decreased bicycle accident rates in the United States by about $.5 \%$ for every $1 \%$ increase in compliance with the standard. In the period covered by our sample, for at least one consumer product, mandatory safety standards resulted in a meaningful reduction in the accident rates associated with using the product. ${ }^{19}$ In the United Kingdom, the results were statistically significant but much more modest. This smaller effect of the standards may reflect their voluntary nature, but we can not test this explicitly. As with any regulatory event study, it is possible that other coincident events were responsible for the reduction in the accident rates. However, this is unlikely, for we analyzed standards issued in two different countries a decade apart, and controlled for other causal factors through the use of seasonal dummy variables, trend, and autocorrelation effects. ${ }^{20}$

It is important to interpret the regulatory effects correctly. The reductions in accident rates associated with the regulations in the two countries result from regulations designed to encourage the manufacture of safer bicycles, but also from any publicity that occurred due to the development and issuance of the regulations and the effects of the regulation on the demand for new bicycles. In the United States, there was considerable 
controversy about an early version of the CPSC bicycle regulations because of their potential effects as a trade barrier (See Cornell, Noll, and Weingast (1976)), and this publicity may have created a stronger focus on safety for both producers and consumers. To the extent that the safety standards raised the cost of producing bicycles, bicycle prices may have been higher, thus leading to reduced sales and a smaller number of bicycles in use. The total impact of the regulations is the sum of the direct impacts from the use of safer bicycles, plus the indirect effects from increased awareness of bicycle safety and a reduced stock of bicycles in use. 


\section{REFERENCES}

Code of Federal Regulations, Commercial Practices. Washington, D.C.: U.S. Government Printing Office, Vol. 16 (1990), Part 1000 to End.

Consumer Safety Unit, Department of Trade and Industry. First through Thirteenth Annual Reports of the Home Accident Surveillance System. London, England, 19781992.

Cornell, N.W., Noll, R.G., and Weingast, B.R. "Safety Regulation." In Henry Owen and Charles L. Schultze, eds., Setting National Priorities: The Coming Decade. Washington: Brookings, 1976.

Linneman, P. "The Effects of Consumer Safety Standards: The 1973 Mattress Flammability Standard," The Joumal of Law and Economics, Vol. 23 (1980), pp. 461-79.

Magat, W.A., and Viscusi, W.K. Informational Approaches to Regulation. Cambridge, MA: MTT Press, 1992.

Moore, M.J. and Viscusi, W.K. "Promoting Safety through Workers' Compensation," Rand Joumal of Economics, Vol. 20, No. 4 (1989), pp. 499-515.

Peltzman, S. "The Effects of Automobile Safety Regulation," Journal of Political Economy, Vol. 83 (1975), pp. 677-725.

. "The Health Effects of Mandatory Prescriptions," The Joumal of Law and Economics, Vol. 30 (1987), pp. 207-39.

Petty, R. D. "The Consumer Product Safety Commission's Promulgation of a Bicycle Safety Standard," Joumal of Products Liability, Vol. 10 (1987), pp. 25-50. 
Rodgers, G.B. "Reducing Bicycle Accidents: A Reevaluation of the Impacts of the CPSC Bicycle Standard and Helmet Use," Journal of Products Liability, Vol. 11 (1988), pp. 307-317.

U.S. Consumer Product Safety Commission. Annual Reports, 1973-1989, Washington, D.C., $1973-1989$.

Viscusi, W. K. . "The Lulling Effect: The Impact of Child-Resistant Packaging on Aspirin and Analgesic Ingestions," American Economic Review, Vol. 74, No. 2 (1984a), pp.324-27.

- Regulating Product Safety. Washington: American Enterprise Institute, 1984b. . "Consumer Behavior and the Safety Effect of Product Safety Regulation," The Joumal of Law and Economics, Vol.27 (1985), pp. 527-53. and Magat, W.A. Learning About Risk: Consumer and Worker Responses to Hazard Information. Cambridge, MA: Harvard, 1987. and Moore, M.J. "Product Liability, Research and Development, and Innovation," Joumal of Political Economy, Vol. 101,No. 1 (1993), pp.161-184. 


\section{FOOTNOTES}

1. See U.S. Consumer Product Safety Commission (1989).

2. The U.S. Consumer Product Safety Commission estimates the costs of consumer product accidents to be $\$ 10$ billion.

3. The same conclusion is also true for other countries, such as the United Kingdom.

4. The 1978 Act strengthened the 1961 Act by making enforcement mandatory, rather than discretionary, and by giving authorities more instruments to control product risks besides standards (e.g., temporary bans, warnings).

5. The standard was challenged in court by a consumer group and two consumers, but with only a few minor exceptions, the standard was upheld.

6. In subsequent years the number of hospitals varied by at most two from the sample sizes in 1978 and 1984.

7. For the bicycle regulation we used product category 1202, bicycles or accessories.

8. We computed bikes in use using industry sales data and product life assumptions provided by the CPSC. Details are available from the authors. Note also that age specific estimates of bicycle use are unavailable. This does not affect the regression results under mild assumptions.

9. In 1989 the Consumer Safety Unit started to collect data on accidents reported to emergency rooms which occurred outside the home, and in 1982 it began the Home Accident Deaths Database (HADD) on fatal accidents. See Consumer Safety Unit (19781992).

10. As in the U.S., age-specific estimates of bicycle use are not available.

11. It is important to note that the descriptive sample characteristics do not use age specific estimates of bicycles in use, as these are, to our knowledge, not available. The heaviest use will almost certainly fall in the three youngest age categories. If, for example, each of these three groups used $25 \%$ of total bikes in use, the estimated mean rates would increase by a factor of four. We do not make such speculative adjustments here.

12. In interpreting the regressions for the United States and the United Kingdom, note that the size of the constant term reflects the fact the denominator is not age-specific. We assume that the proportion of bikes used by each age group is fairly constant over the sample period. Failure to make the denominator age-specific under this assumption will 
inflate the value of the constant term slightly.

13. The \% Complying variable under the seven year product life assumption ranges from 0 to $26 \%$. At the upper limit of this range, the elasticity estimates would equal $0.65-0.83$.

14. Over the period 1972-74, the domestic bicycle market (domestic shipments and importsexports) averaged about 14 million units shipped. By way of contrast, average shipments for 1968-71 equalled about seven million. In 1975, shipments equalled about eight million bicycles, and varied between eight and ten million through the remainder of the sample period.

15. The two studies also differ in that Viscusi used the 1978 publication date of the regulations in the Code of Federal Regulations, whereas we used the November 13, 1975 publication date of the revised final standard in the Federal Register.

16. The data were taken from Chapter Seven, "Cycling," pp. 41-45, of National Traffic Survey: 1989/91, Great Britain Department of Transport, London: HMSO (September 1993). An alternative, and perhaps preferred, measure of risk exposure is accidents per bicycle mile. Here, we use accidents per bicycle for comparability with the U.S. results. Results from the U.K. using accidents per mile are similar to those reported here.

17. We would expect the measured U.K. accident rates to be lower because they exclude accidents outside the home and yard, which are included in the U.S. statistics.

18. Although it might seem odd to find zeroes in a "national" accident series, remember that the HASS data are based on a sample of 20 hospitals, and that we aggregated them monthly by age group. Thus, a zero does not imply that there were no accidents anywhere in the United Kingdom. Rather, it reflects sampling error.

19. Extrapolations beyond small variations appear unwarranted. Evaluating the results at "full compliance," for example, where \% Complying $=100$, gives an unreasonably large effect.

20. Increases in helmet use are not a factor in explaining the impact of the CPSC regulations. Petty (1987) provides data on helmet use indicating that helmets were not worn by many riders in the 1972-1978 period, and helmet use did not reach even one-quarter of its 1985 level until 1980. 


\section{Table 1}

U.S. Bicycles Mean Deseasonalized Monthly Injury Rates per Million Bicycles in Use, by Age Category Seven Year Product Life

Age of Injured Persons

Mean

(std Deviation)

0-4

29.0

(9.6)

5-9

73.8

(2.1)

10-14

Data Sources: Monthly injury rates from National Electronic Injury Surveillance System (NEISS), Consumer Product Safety Commission. Sample includes December, 1972September, 1978. Bicycle data from Schwinn Sales, Inc. (1982). Population data from Statistical Abstract of the United States. Each age category contains 70 monthly averages of injury rates. 
Table 2

U.S. Bicycle Industry

Age-Specific Injury Rates and Their Growth Rates ${ }^{a}$

Pre- and Post-Regulation

Seven Year Product Life

(Means with Deseasonalized Standard Deviations in Parentheses)

\begin{tabular}{|c|c|c|c|c|}
\hline \multirow{2}{*}{$\begin{array}{l}\text { Age of } \\
\text { Injured Persons }\end{array}$} & \multicolumn{2}{|c|}{ Injury Rate (per million bicycles) } & \multicolumn{2}{|c|}{ \% Change in Injury rate } \\
\hline & Preregulation & Post-regulation & Prerequlation & Post-regulation \\
\hline $0-4$ & $\begin{array}{c}34.2 \\
(8.8)\end{array}$ & $\begin{array}{l}23.0 \\
(7.4)\end{array}$ & $\begin{array}{c}.004 \\
(.004)\end{array}$ & $\begin{array}{c}-.014^{b} \\
.006\end{array}$ \\
\hline $5-9$ & $\begin{array}{c}76.7 \\
(22.7)\end{array}$ & $\begin{array}{c}70.8 \\
(16.9)\end{array}$ & $\begin{array}{c}.006 \\
(.006)\end{array}$ & $\begin{array}{c}.003 \\
(.004)\end{array}$ \\
\hline $10-14$ & $\begin{array}{l}68.2 \\
(2.4)\end{array}$ & $\begin{array}{c}57.7 \\
(15.9)\end{array}$ & $\begin{array}{l}.002 \\
(.005)\end{array}$ & $\begin{array}{l}-.009^{c} \\
(.004)\end{array}$ \\
\hline $15-19$ & $\begin{array}{l}15.4 \\
(8.7)\end{array}$ & $\begin{array}{l}14.0 \\
(4.1)\end{array}$ & $\begin{array}{c}.002 \\
(.008)\end{array}$ & $\begin{array}{c}.006 \\
(.004))\end{array}$ \\
\hline $20-24$ & $\begin{array}{c}3.1 \\
(2.8)\end{array}$ & $\begin{array}{c}3.1 \\
(2.0)\end{array}$ & $\begin{array}{c}.006 \\
(.018)\end{array}$ & $\begin{array}{c}.007 \\
(.014)\end{array}$ \\
\hline $25-29$ & $\begin{array}{c}3.0 \\
(2.8)\end{array}$ & $\begin{array}{c}2.6 \\
(2.9)\end{array}$ & $\begin{array}{c}.003 \\
(.013)\end{array}$ & $\begin{array}{l}.015 \\
(.013)\end{array}$ \\
\hline $\begin{array}{l}\text { Observations } \\
\text { per age group }\end{array}$ & 35 & 35 & 35 & 35 \\
\hline $\begin{array}{l}\text { Data Sources: } \\
\text { (NEISS), Consu } \\
\text { September, } 1978 \\
\text { Statistical Abstr } \\
\text { averages of inju } \\
\text { ' Statistically sig } \\
\text { ' Statistically sig }\end{array}$ & $\begin{array}{l}\text { icycle data fro } \\
\text { of the United } \\
\text { tes. } \\
\text { cant, } .01 \text { confic } \\
\text { ant, } .05 \text { confic }\end{array}$ & $\begin{array}{l}\text { from National E } \\
\text { Commission. Sa } \\
\text { Schwinn Sales, I } \\
\text { tes. Each age c } \\
\text { ice level. } \\
\text { ce level. }\end{array}$ & $\begin{array}{l}\text { ectronic Injury } \\
\text { nple includes I } \\
\text { c. (1982). Pop } \\
\text { ategory contain }\end{array}$ & $\begin{array}{l}\text { urveillance System } \\
\text { cember, } 1972- \\
\text { ation data from } \\
70 \text { monthly }\end{array}$ \\
\hline
\end{tabular}


Table 3

\author{
U.S. Bicycle Monthly Injury Rate Regressions \\ Seven Year Product Life \\ Dependent Variable $=$ ln (Injuries per Million Bicycles) \\ Estimated Coefficients and Standard Errors
}

\begin{tabular}{|c|c|c|c|c|}
\hline \multirow[b]{2}{*}{ Variable } & \multicolumn{3}{|c|}{$0 \leq$ Age $<5$} & \multirow[b]{2}{*}{$(4)$} \\
\hline & (1) & (2) & (3) & \\
\hline Constant & $\begin{array}{l}2.252^{\mathrm{b}} \\
(.110)\end{array}$ & $\begin{array}{l}2.258^{b} \\
(.177)\end{array}$ & $\begin{array}{l}2.362^{b} \\
(.145)\end{array}$ & $\begin{array}{l}2.269^{b} \\
(.259)\end{array}$ \\
\hline$\%$ Complying & $\begin{array}{r}-2.507^{b} \\
(.576)\end{array}$ & $\begin{array}{r}-2.473^{b} \\
(.951)\end{array}$ & $\begin{array}{r}-2.567^{b} \\
(.753)\end{array}$ & $\begin{array}{l}-3.240^{b} \\
(1.354)\end{array}$ \\
\hline Spring & $\begin{array}{l}1.326^{\mathrm{b}} \\
(.147)\end{array}$ & $\begin{array}{l}1.327^{b} \\
(.149)\end{array}$ & $\begin{array}{l}1.183^{b} \\
(.170)\end{array}$ & $\begin{array}{l}1.126^{\mathrm{b}} \\
(.176)\end{array}$ \\
\hline Summer & $\begin{array}{l}1.790^{\mathrm{b}} \\
(.149)\end{array}$ & $\begin{array}{l}1.791^{b} \\
(.153)\end{array}$ & $\begin{array}{l}1.570^{\mathrm{b}} \\
(.203)\end{array}$ & $\begin{array}{l}1.484 \mathrm{a}^{\mathrm{b}} \\
(.219)\end{array}$ \\
\hline Fall & $\begin{array}{l}.765^{\mathrm{b}} \\
(.150)\end{array}$ & $\begin{array}{l}.766^{\mathrm{b}} \\
(.152)\end{array}$ & $\begin{array}{l}.687^{\mathrm{b}} \\
(.192)\end{array}$ & $\begin{array}{l}.661^{b} \\
(.203)\end{array}$ \\
\hline Trend & - & $\begin{array}{c}-1.92 E-4 \\
(43.31 E-4)\end{array}$ & - & $\begin{array}{c}.004 \\
(.007)\end{array}$ \\
\hline Adjusted R2 & .721 & .717 & .726 & .723 \\
\hline$\rho^{d}$ & - & - & $\begin{array}{l}.259^{b} \\
(.147)\end{array}$ & $\begin{array}{r}.315^{\mathrm{b}} \\
(.149)\end{array}$ \\
\hline
\end{tabular}

D-W Statistic

1.725

1.727

Data Sources: Monthly injury rates from National Electronic Injury Surveillance System (NEISS), Consumer Product Safety Commission. Sample includes December, 1972September, 1978. Bicycle data from Schwinn Sales, Inc. (1982). Population data from Statistical Abstract of the United States. Each age category contains 70 monthly averages of injury rates.

b Significant at the .01 level, one-tailed test.

c Significant at the .05 level, one-tailed test.

d First order autocorrelation coefficient 
Table 4

U.S. Bicycle Injury Regressions

Seven Year Product Life

Summary of Regulation Effects

Dependent Variable $=$ en (Injuries per Million Bicycles)

Seven Year Product Life

\begin{tabular}{llll}
\multicolumn{4}{c}{ Age } \\
\hline $0-4$ & $5-9$ & $10-14$ & $15-19$
\end{tabular}

\% Complying

$-3.240^{\circ}$
$(1.354)$

$-4.906^{c}$

$-4.265^{c}$

(1.915)

. .665

(1.354)

(2.298)

$(1.360)$

Adjusted R ${ }^{2}$

.723

.739

.752

.670

$\rho^{d}$

$.315^{b}$

$.752^{\circ}$

(.113)

$.704^{b}$

$.280^{c}$

(.149)

(.118)

(.133)

Ten Year Product Life

$\%$ Complying

$-4.189^{b}$
$(1.707)$

$-6.062^{c}$

$-5.326^{\mathrm{c}}$

(2.389)

.894

(2.849)

(1.703)

Adjusted $\mathrm{R}^{2}$

.725

.751

.753

.668

$\rho^{d}$

$.349^{c}$

$.751^{\mathrm{b}}$

$.707^{\mathrm{b}}$

(.114)

(.117)

$.287^{c}$

(.149)

(.133)

Data Sources: Monthly injury rates from National Electronic Injury Surveillance System (NEISS), Consumer Product Safety Commission. Sample includes December, 1972September, 1978. Bicycle data from Schwinn Sales, Inc. (1982). Population data from Statistical Abstract of the United States. Each age category contains 70 monthly averages of injury rates.

'Significant at the .01 level, one-tailed test.

c Significant at the .05 level, one-tailed test.

- First order autocorrelation coefficient. 
Table 5

U.K. Bicycle Industry

Age-Specific Injury Rates and Their Growth Rates

Pre- and Post-Regulation

Seven Year Product Life

(Means with Deseasonalized Standard Deviations in Parentheses)

\begin{tabular}{|c|c|c|c|c|}
\hline \multirow{2}{*}{$\begin{array}{l}\text { Age of } \\
\text { Injured Persons }\end{array}$} & \multicolumn{2}{|c|}{ Injury Rate (per million bicycles) } & \multicolumn{2}{|c|}{ \%o Change in Injury rate } \\
\hline & Preregulation & Post-regulation & Preregulation & Post-regulation \\
\hline $0-4$ & $\begin{array}{c}96.8 \\
(30.0)\end{array}$ & $\begin{array}{l}55.5 \\
(4.36)\end{array}$ & $\begin{array}{l}-.009^{a} \\
(.002)\end{array}$ & $\begin{array}{l}-.007 \\
(.008)\end{array}$ \\
\hline $5-9$ & $\begin{array}{c}50.3 \\
(22.6)\end{array}$ & $\begin{array}{c}36.2 \\
(17.9)\end{array}$ & $\begin{array}{l}.003^{b} \\
(.002)\end{array}$ & $\begin{array}{l}-.004 \\
(.007)\end{array}$ \\
\hline $10-14$ & $\begin{array}{c}23.6 \\
(12.6)\end{array}$ & $\begin{array}{l}16.4 \\
(9.6)\end{array}$ & $\begin{array}{l}.001 \\
(.001)\end{array}$ & $\begin{array}{l}-.002 \\
(.003)\end{array}$ \\
\hline $15 \cdot 19$ & $\begin{array}{c}9.7 \\
(8.7)\end{array}$ & $\begin{array}{c}3.8 \\
(3.8)\end{array}$ & $\begin{array}{l}-2.1 \mathrm{E}-4 \\
(3.4 \mathrm{E}-4)\end{array}$ & $\begin{array}{c}-2.1 \mathrm{E}-4 \\
(10.5 \mathrm{E}-3)\end{array}$ \\
\hline $20-24$ & $\begin{array}{c}3.3 \\
(4.0)\end{array}$ & $\begin{array}{c}3.2 \\
(3.9)\end{array}$ & $\begin{array}{l}-3.0 \mathrm{E}-4^{\mathrm{b}} \\
(1.7 \mathrm{E}-4)\end{array}$ & $\begin{array}{c}2.8 \mathrm{E}-4 \\
(5.6 \mathrm{E}-4)\end{array}$ \\
\hline
\end{tabular}

a Data Sources: Monthly injury rates from Household Accident Surveillance System (HASS), Department of Trade and Industry. Bicycle use data from national Traffic Survey, 1989/91. Population data from Statistical Review of England and Wales (various years).

Significant at the .01 confidence level, one-tailed test.

' Significant at the .05 confidence level, one-tailed test. 
Table 6

U.K. Bicycle Injury Regressions

Seven Year Product Life

Dependent Variable $=$ en (Injuries per Million Bicycles)

Estimated Coefficients and Standard Errors

$0 \leq \mathrm{Age}<5$

\begin{tabular}{|c|c|c|c|c|}
\hline & (1) & $(2)$ & $(3)$ & $(4)$ \\
\hline Constant & $\begin{array}{l}3.547^{b} \\
(.099)\end{array}$ & $\begin{array}{c}3.808^{b} \\
(4.128)\end{array}$ & $\begin{array}{l}3.953^{b} \\
(.154)\end{array}$ & $\begin{array}{l}4.239^{b} \\
(.220)\end{array}$ \\
\hline \% Complying & $\begin{array}{r}-2.369^{\mathrm{b}} \\
(.618)\end{array}$ & $\begin{array}{c}.581 \\
(.836)\end{array}$ & $\begin{array}{l}-2.714^{c} \\
(1.156)\end{array}$ & $\begin{array}{c}-.764 \\
(1.344)\end{array}$ \\
\hline Spring & $\begin{array}{l}1.079^{b} \\
(.138)\end{array}$ & $\begin{array}{l}1.117^{b} \\
(.133)\end{array}$ & $\begin{array}{c}.656^{\mathrm{b}} \\
(.149)\end{array}$ & $\begin{array}{c}.737^{b} \\
(.146)\end{array}$ \\
\hline Summer & $\begin{array}{l}1.389^{\mathrm{b}} \\
(.140)\end{array}$ & $\begin{array}{l}1.431^{b} \\
(.134)\end{array}$ & $\begin{array}{c}.669^{c} \\
(.173)\end{array}$ & $\begin{array}{r}.820^{\circ} \\
(.166)\end{array}$ \\
\hline Fall & $\begin{array}{r}.489^{b} \\
(.140)\end{array}$ & $\begin{array}{c}511^{\mathrm{b}} \\
(.134)\end{array}$ & $\begin{array}{c}.098^{b} \\
(.155)\end{array}$ & $\begin{array}{c}.172 \\
(.151)\end{array}$ \\
\hline Trend & - & $\begin{array}{l}-.008^{b} \\
(.003)\end{array}$ & - & $\begin{array}{c}-.010^{c} \\
(.005)\end{array}$ \\
\hline Adjusted $\mathbf{R}^{2}$ & .610 & .644 & .252 & .344 \\
\hline $\mathbf{P}$ & - & - & $\begin{array}{c}.577^{\circ} \\
(.084)\end{array}$ & $\begin{array}{c}.480^{\circ} \\
(.088)\end{array}$ \\
\hline
\end{tabular}

Data Sources: Monthly injury rates from Household Accident Surveillance System (HASS), Department of Trade and Industry. Population data from Statistical Review of England and Wales (various years). Bicycle data from National Traffic Survey, 1989/91, Great Britain Department of Transport, London: HMSO (1993).

b Significant at the .01 confidence level, one-tailed test.

c Significant at the .05 confidence level, one-tailed test. 
Table 7

U.K. Bicycle Injury Rate Regression

Seven Year Product Life

Summary of Regulation Effects

Dependent Variable $=$ en (Injuries Per Million Bicycles)

\begin{tabular}{|c|c|c|c|c|}
\hline & \multicolumn{3}{|c|}{ Age } & \\
\hline & $0-4$ & 5.9 & $10-14$ & $15 \cdot 19$ \\
\hline \% Complying & $\begin{array}{c}-.764 \\
(1.344)\end{array}$ & $\begin{array}{l}-1.739^{c} \\
(1.031)\end{array}$ & $\begin{array}{l}-1.162 \\
(1.460)\end{array}$ & $\begin{array}{l}-2.263^{\mathrm{b}} \\
(1.246)\end{array}$ \\
\hline Trend & $\begin{array}{l}-.010^{b} \\
(.005)\end{array}$ & $\begin{array}{c}.001 \\
(.003)\end{array}$ & $\begin{array}{c}.001 \\
(.005)\end{array}$ & $\begin{array}{l}-.005 \\
(.004)\end{array}$ \\
\hline Adjusted $\mathbf{R}^{2}$ & .344 & .693 & 279 & .216 \\
\hline$p^{d}$ & $\begin{array}{r}.498^{\mathrm{b}} \\
(.088)\end{array}$ & $\begin{array}{l}-.092 \\
(.1057\end{array}$ & $\begin{array}{c}.094 \\
(.111)\end{array}$ & $\begin{array}{l}-.123 \\
(.117)\end{array}$ \\
\hline
\end{tabular}

Data Sources: Monthly injury rates from Household Accident Surveillance System (HASS), Department of Trade and Industry. Population data from Statistical Review of England and Wales (various years). Bicycle data from National Traffic Survey, 1989/91, Great Britain Department of Transport, London: HMSO (1993).

'Significant at the .01 level, one-tailed test.

c Significant at the .05 level, one-tailed test.

d First order autocorrelation coefficient. 
Figure 1: Annual Injury Rates, 1977-88. United States

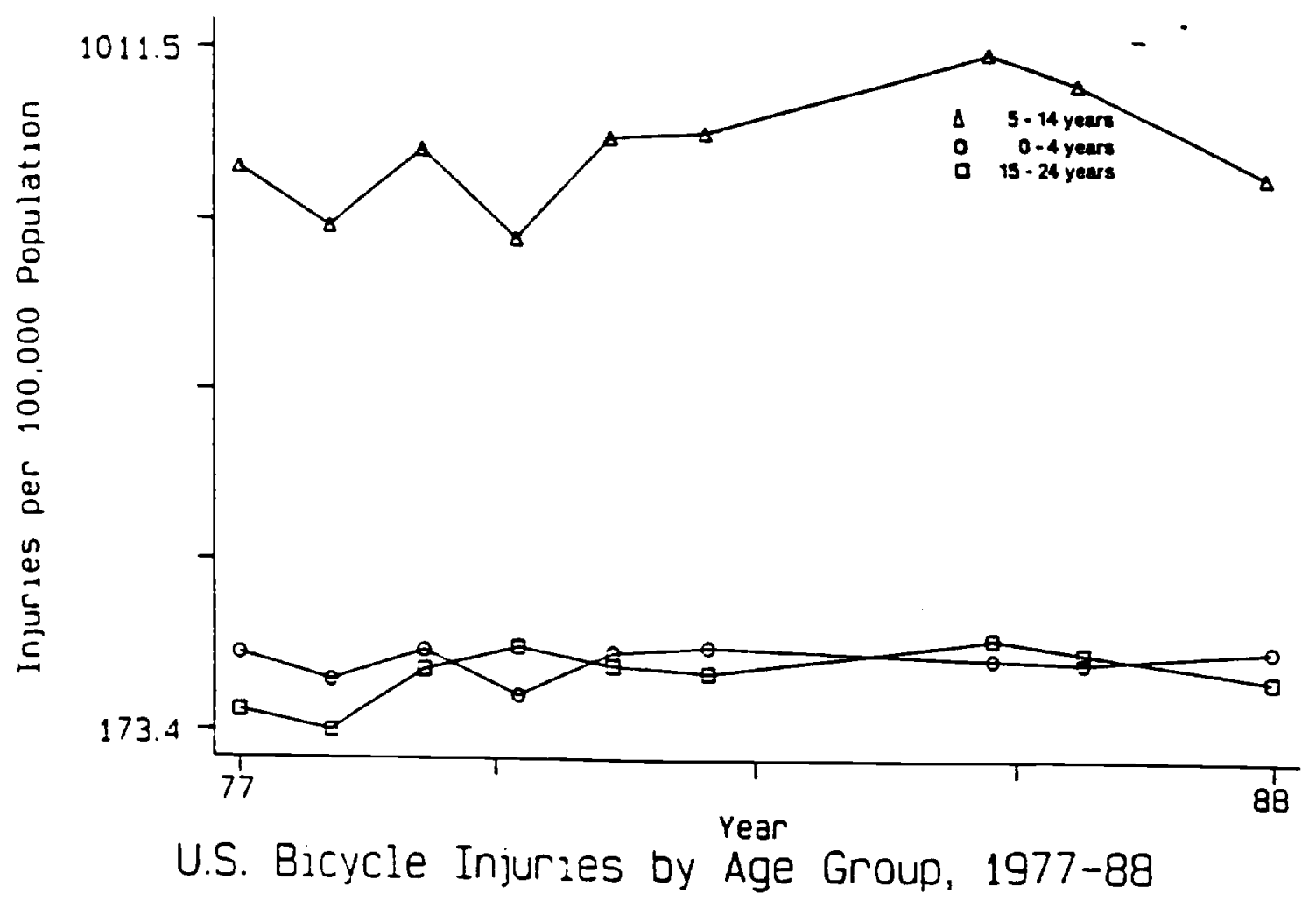

STETa"

Data from NEISS, annual averages by age group (1983-85 data not available). See NEISS Data Highlights, Consumer Product Safety Commission (various years). 
FIGURE 2: U.S. Injuries by Season

December, 1972 - September, 1978
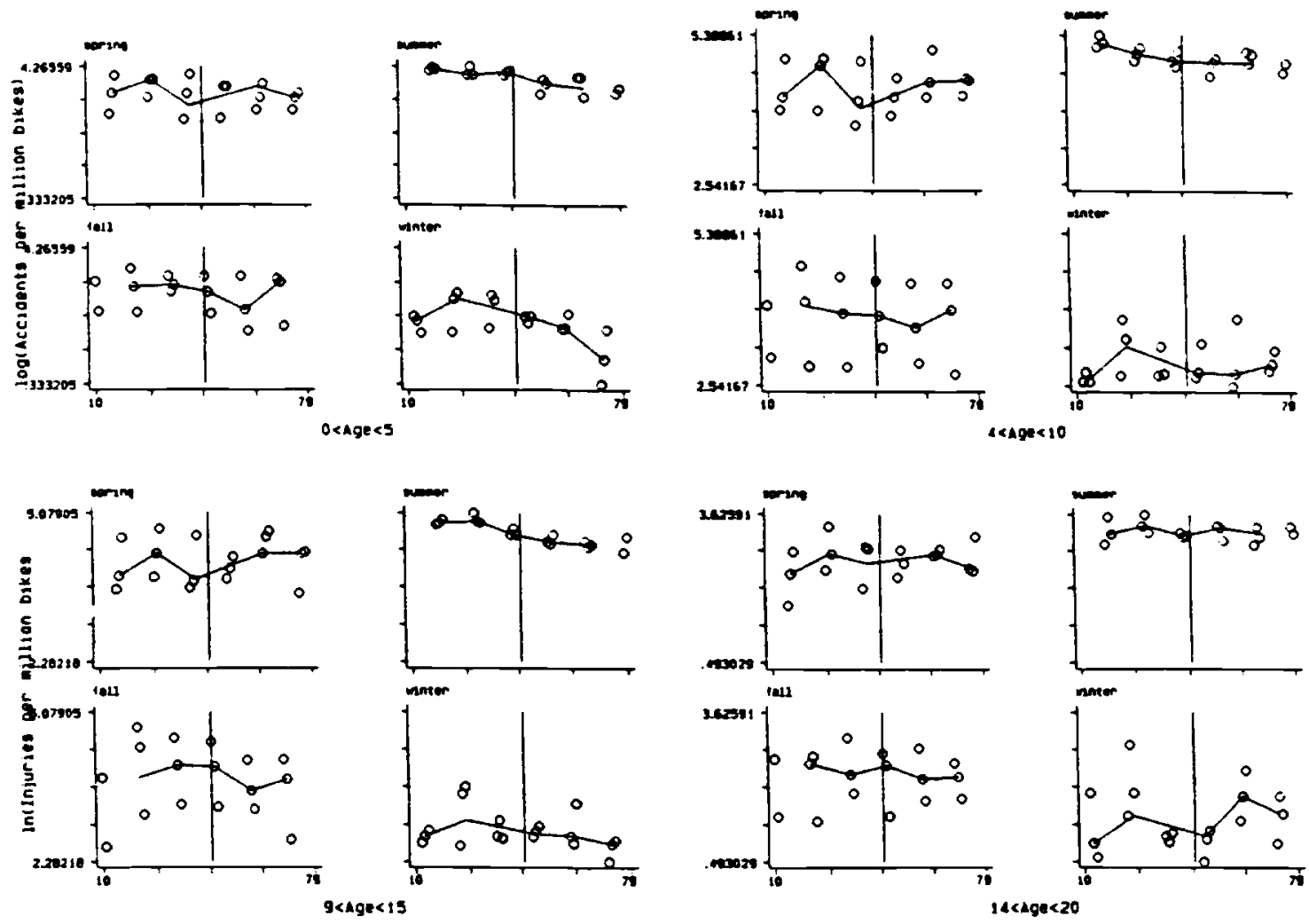

$\overline{\text { श्रि" }}$

- Horizontal axis denotes month. In the U.S. data, these range from December, 1972 (month $=10)$ to September, 1978 (month $=79$ ). 
Moore

Fig. 3 of 3

FGURE 3: U.K. Injuries by Season

November, 1979 - April, 1987
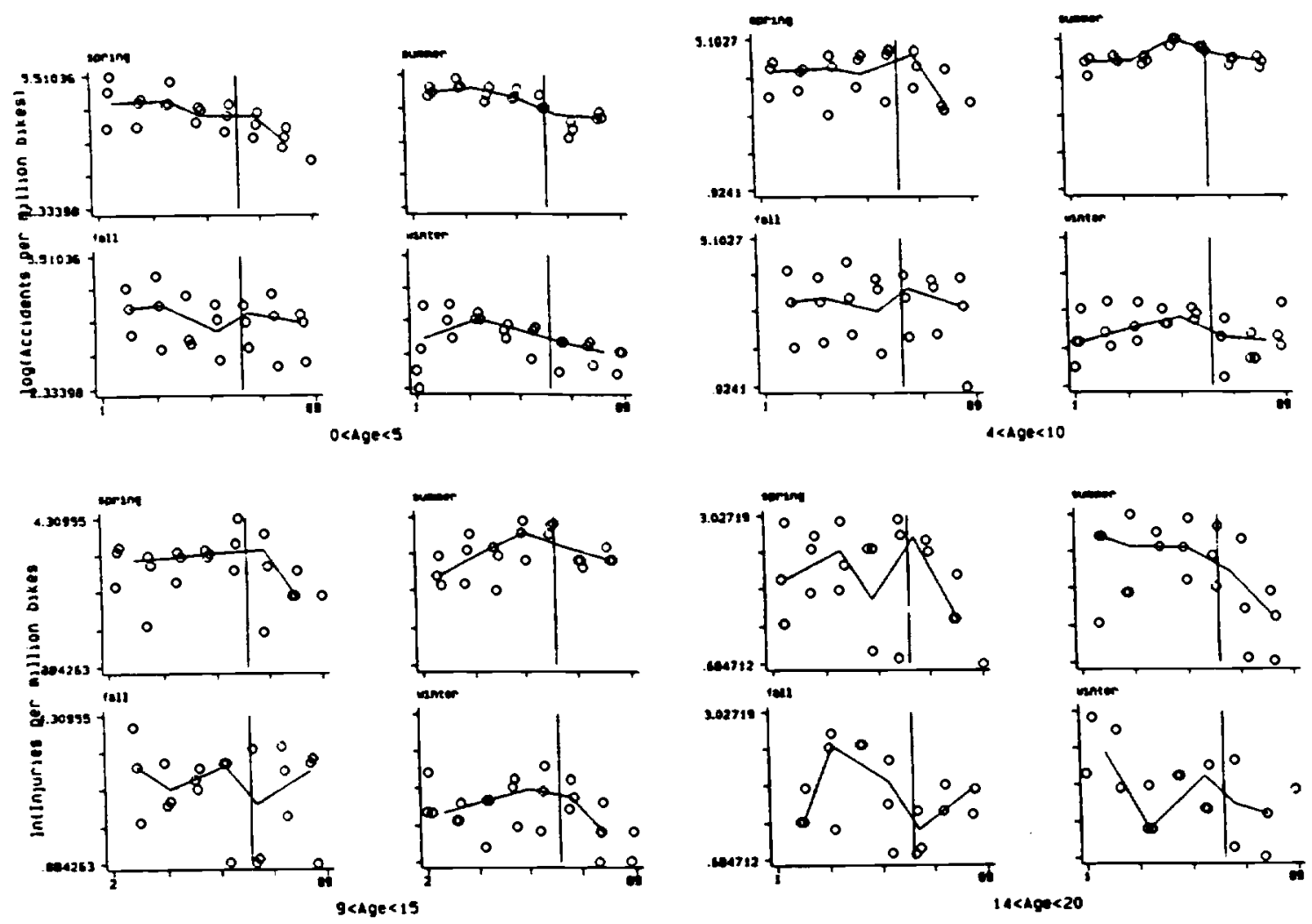

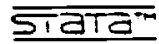

- Horizontal axis denotes month. In the U.K. data, these range from November, $1979($ month $=1)$ to April, 1987 (month $=89$ ).

35 